\title{
Once Upon a Time in Animation: Curatorial strategies for an exhibition on the National Centre for Computer Animation
}

\author{
Oliver Mag Gingrich \\ National Centre for Computer \\ Animation, London, UK \\ gingricho@bournemouth.ac.uk
}

\author{
Claudia Fasola-Moore \\ Curator, Researcher \\ Dorset, UK \\ Claudiafasolamoore@gmail.com
}

\author{
Eike Falk Anderson \\ National Centre for Computer \\ Animation, Dorset, UK \\ mailto:eanderson@bournemouth.ac.uk
}

\begin{abstract}
The National Centre for Computer Animation at Bournemouth University is developing a digital collection of historical assets arising from 30 years of pioneering work. These rare assets of late 20th and early 21st century animation include high quality digital and hardcopy storyboards, animatics and completely rendered scenes. This unique collection will be presented publicly at an exhibition at Poole Museum entitled 'Once Upon A Time in Animation'. This paper will describe the creation of the archive and collection as well as the curatorial strategy of making it accessible to the public. What are the most relevant artefacts of $\mathbf{3 0}$ years of Animation at this world leading institution? What are the best strategies in making Animation accessible to future talents? How can we strengthen the role of the South West of England as one of the major hubs in Animation, VFX and the Creative Industries?
\end{abstract}

\section{Animation history. Digital collection. Digital artefact. Curatorial strategies.}

\section{INTRODUCTION}

Since its inception in 1989 by Peter Hardy and Peter Cominos, the National Centre for Computer Animation (NCCA) has remained at the forefront of computer animation techniques, visual effects, compositing and post-production. Established at Bournemouth University due to its existing reputation for animation and computer graphic expertise, the National Centre for Computer Animation has long held a pivotal role for education in the creative industries.

Poole Museum is one of the leading museums in the South West of England, showcasing a range of historic artefacts in their permanent collection as well as a changing array of diverse historic and contemporary art projects. Poole Museum is located in three adjacent buildings, housed at a historic Victorian warehouse, the Oakley's Mill located at the heart of Poole. Its iconic facade was designed by Horden Cherry Lee. Inside, the building connects to the historic Town cellars built around 1300.

The exhibition 'Once Upon A Time in Animation' scheduled for Summer 2020 at Poole Museum will highlight the special role of animation, gaming and visual effects held in the Southwest of England. The whole region has made a name for its expertise, in large part thanks to Bournemouth University's unique role as a pioneer in education and research for the Creative Industries.

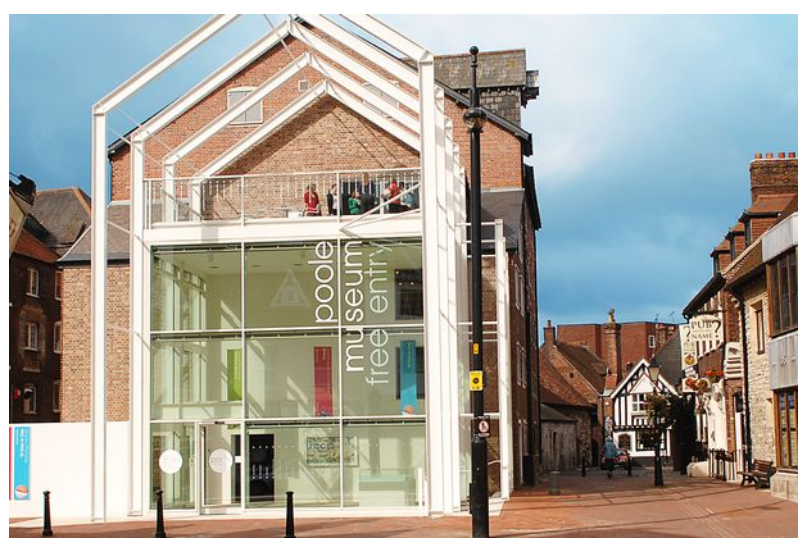

Figure 1: Poole Museum, the most popular free attraction in Dorset.

\section{30 YEARS OF EDUCATION \& RESEARCH}

The NCCA stands in the tradition of Bournemouth University's motto, 'Discere mutari est' just states "to learn is to change" - in brief, to inspire learning, to advance knowledge and to enrich society. Bournemouth's University's 'Fusion' principle, 
derived from Humbolt's 'Bildungsideal' brings research, education and practice together, to ensure synergies between these different areas of higher education. Since its inauguration, the NCCA has found itself on the intersection between industry and research, a position that assured the continuing proximity of taught intended learning outcomes to state-of-the-art industry practices, guaranteeing demand for and employability of its students, while strengthening the significance of the centre's research in artistic and scientific practice.

The NCCA continues its excellent reputation through its presence at the world's foremost forums for computer graphics discourse such as Siggraph (Comninos et al. 2010), Eurographics and the creation and running an internationally renowned festival for animation and visual effects. The BFX Festival is known as the UK's largest festival for animation and visual effects.

\section{ONCE UPON A TIME IN ANIMATION}

Conceptualised by Claudia Fasola-Moore and Poole Museum's Rebecca Rossiter and Michael Spender, the exhibition has now received support by the Arts Council England and National Lottery Heritage Fund. Curated by Oliver Gingrich, Eike Anderson and Claudia Fasola Moore, the exhibition aims to convey the ethos of the NCCA: to be open, inclusive, creative, to reflect on the joy of animation \& learning. It is under this credo that the exhibition at Poole Museum will transcend its research and practices to the wider public. Under the title 'Once upon a time in Animation' the doors of Poole Museum will open for 6 weeks, to showcase historic and contemporary practices, research outputs and applications.

Embedded in a rich framework of talks, workshops, and career building activities, the exhibition will address an audience of all ages, directed towards the region's local communities, creative industry aficionados as well as the large pool of international visitors to the region during the Summer months.

Conceptually the exhibition spans a narrative arc between contemporary practices, methods and techniques of animation including the NCCA's areas of expertise such as shading, rendering, and real-time animation. The exhibition will present outstanding research in the name of art and science, applications of animation such as art, medicine and gaming, while showcasing cornerstone pieces symbolising the past, presence and future of the NCCA.

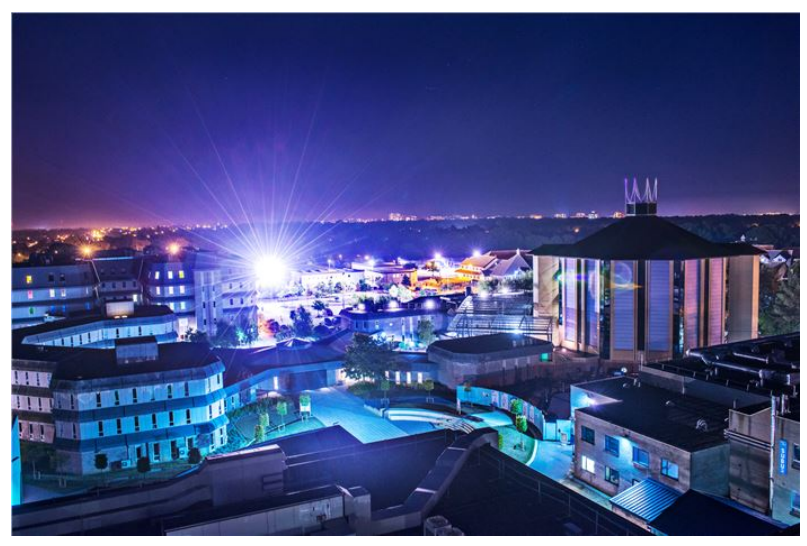

Figure 2: Bournemouth University, home of the National Centre for Computer Animation.

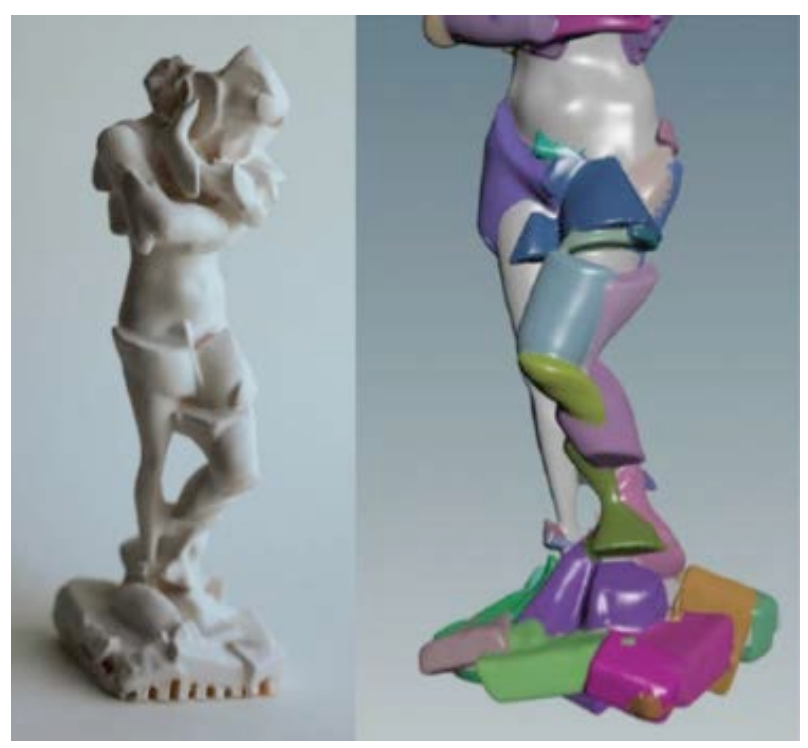

Figure 3: Valery Adzhiev 3D 4D cubism project 'Eve'.

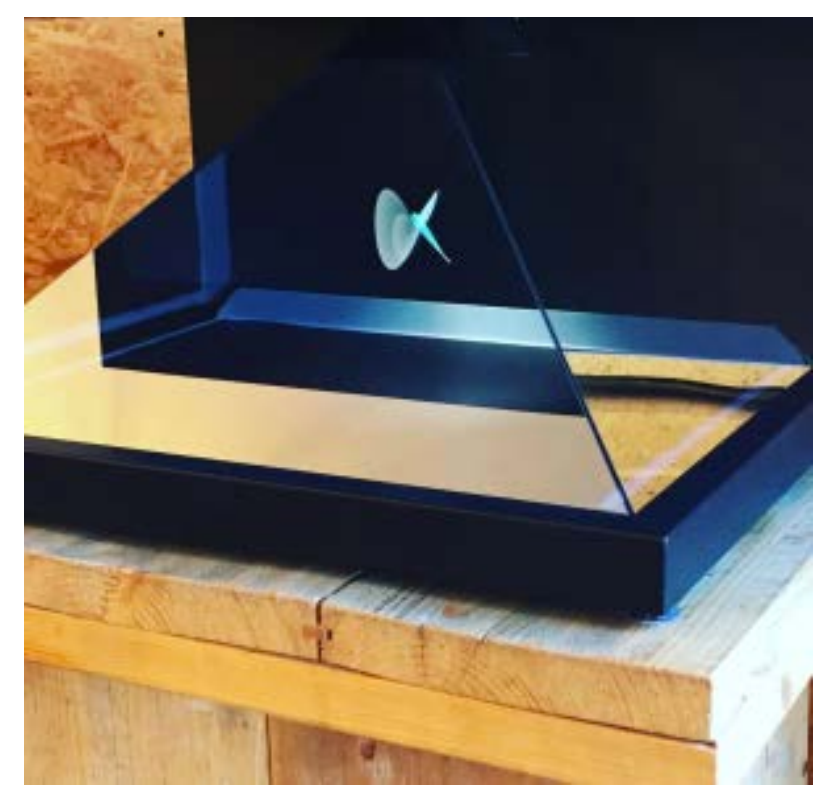

Figure 4: Oliver Gingrich 'Ghost in the Machine' Hologram. 


\section{CURATORIAL STRATEGY}

For this landmark show, Bournemouth University and the NCCA are profiling some of their most important artists, graduates, researchers and partners such as Aardman animation, Blue Zoo and others to present the Art of Animation to all new audiences. 'Once Upon A Time in Animation' invites families, national and international visitors, Creative Industries, and wider audiences such as schools, local communities and all those interested in Animation to experience animation as applied research, as artistic practice, as technology enabled creativity and as a medium of the future.

New practices such as photogrammetry, 3D printing (Valery Adzhiev: See Figure 2), real-time animation and family favourites such as interactive green screen, original storyboards, a gaming zone, and holograms (Figure 4) will excite audiences of all ages. The audience will be able to gain insight into animation and visual effects practices, methods and techniques, innovations and technical developments. Furthermore, we are looking to provide a deeper understanding of animation as a career path, as an applied art form, with a multitude of different fields of engagement such as gaming, medicine, 3D printing and heritage conservation and many more.

Importantly, the exhibition will serve as a platform to launch the new NCCA archive, a collection of storyboards, concept boards and artefacts donated to the research centre by world leading companies such as Aardman, CBBC, and Blue Zoo, as well as NCCA graduates and alumni.

\section{NCCA COLLECTION}

'Once Upon a Time in Animation' will launch the NCCA archive, a collection of assets, artefacts, storyboards, animations, animatics, concept art works, and heritage pieces from the NCCA's 30 year long history. Our archive website will use tags and categories system slightly differently. Since tags can't be arranged into a hierarchy, we use them to determine whether a single post entry contains animatics, storyboards, pre-vis, all, or some of the above. A single post tagged "animatic" will show up in the "Animatics" section of the website. A single post tagged "storyboard" as well as "pre-vis" will show up in both "Storyboard" and "Pre-Vis" sections of the website. The website will be linked to $\mathrm{QR}$ codes which will be displayed at the exhibition, so audiences can learn about the artefacts through further reading online and share these posts with their peers. The breadth and scope of 'Once Upon a Time in Animation' will ensure to inspire future generations of Animators and VFX artists.

\section{FRAMEWORK PROGRAM}

The framework program has been developed to address a family friendly audience offering a wide range of activities: From workshops to create your own mobile app, to stop trick animation, from 3D printing to career workshops, the events have been designed with a focus on offering a wide variety of activities parents will be able to enjoy as much as their children.

Participants will be able to create their own robots, will learn about coding in Raspberry Pi workshops and to create their own video games. Orchestrated by Claudia Moore and Dr. Oleg Fryazinov, these workshops will run every weekend, over the course of the exhibition. On three Friday afternoons, a teenage audience will be invited to learn about career paths within the creative industries, to highlight future opportunities for the next generation of VFX artists and animators.

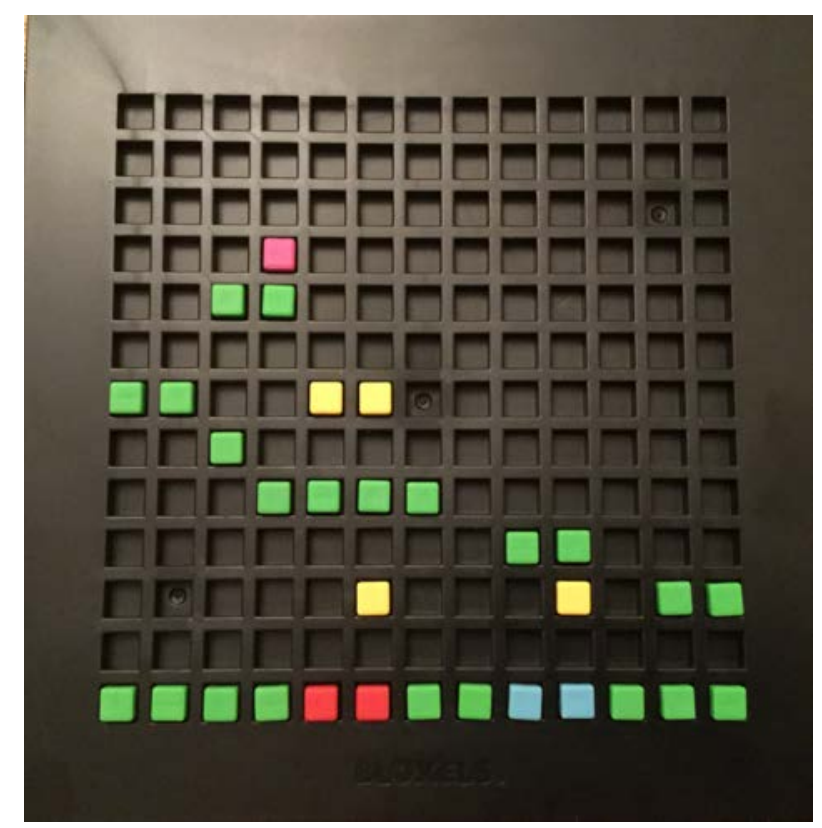

Figure 5: Bloxel board for Pixel Art workshops.

\section{CRITICAL ANALYSIS}

Curatorial decisions will need to strike a fine balance between resources, floor space, and the themes of the exhibition. The key objective is to celebrate BU's and the NCCA ascent to one of the leading institutions in animation worldwide, by staying close to BU's brand recognition code to assure that the exhibition can build on BU's fantastic image in the region. We will target a diverse audience with a key focus on local residents, community groups, families and all ages, as well as minority groups and audiences who need access support as well as national and international audiences. 
Our aim is to inspire future learning, to awaken an interest in the NCCA's history, its collection and its future as a major research hub for computer animation. With the exhibition and its framework programming, we want to contribute to Knowledge Exchange, connecting between local businesses, creative entrepreneurs and SMEs and the academic community through talks and active debates. It will be testament to the success of the exhibition, if we can excite audiences of all ages, the alumni and creative pioneers as much as the next generation of animators visiting the exhibition.

\section{CONCLUSION}

In a climate when curatorial practices are often criticised for turning the museum into an attraction, the exhibition 'Once Upon a Time in Animation' will seek to provide insights into research, historic developments and technological advances, by maintaining an experiential focus. The exhibition will consolidate disparaging viewpoints fusing playfulness of animation, with artistry, joy of technological progress with its creative potential.

\section{REFERENCES}

Bishop, C. Artifical Hells (2012) Participatory Art and the Politics of Spectatorship. Verso books, London.

Comninos, P., McLoughlin, L., Anderson E. F. (2010) Educating technophile artists and artophile technologists: A successful experiment in higher education. Computers \& Graphics: An International Journal of Systems \& Applications in Computer Graphics, 34 pp.780-790.

Gingrich, O., Renaud A., Emets, E., and Aura, A. (2019) Aura: A holographic brainwave interface. EVA London 2019 (Electronic Visualisation and the Arts). doi: $10.14236 /$ ewic/EVA2018.66 